\title{
高寒草甸土地退化及其恢复重建对植被 碳、氮含量的影响
}

\author{
王文颖 ${ }^{13}$ 王启基 $^{2 *}$ 王 刚 $^{3}$ 景增春 $^{2}$ \\ (1 青海师范大学青藏高原环境与资源教育部重点实验室, 西宁 810008) \\ (2 中国科学院西北高原生物研究所, 西宁 810001) (3 兰州大学生命科学学院, 兰州 730000)
}

摘 要 以青海省达日县高寒草甸原生高寒嵩草 (Kobresia) 草甸封育系统为对照, 研究了土地退化对植被生产力的 影响，检验了不同人工重建措施(两个人工种植处理 混播 $(\mathrm{HB}$ )、翻耕单播 $(\mathrm{DBF})$ 和 1 个退化草地封育自然恢复处理 (NR) 及 1 个退化草地自然状态(SDL)) 对植被生产力的相对影响程度。结果表明, 原生植被封育处理 (YF) 地上总生 物量为 $265.1 \mathrm{~g} \mathrm{~m}^{-2}$, 混播 (HB) 和翻耕单播( DBF) 处理中地上总生物量分别为原生植被封育处理的 $116 \%$ 和 $68 \%$ 。 退化草地封育自然恢复处理 $(\mathrm{NR})$ 和重度退化自然状态下地上总生物量分别为原生植被封育的 76\%和 53\%。YF 处 理根系生物量远大于其它处理。原生植被封育系统中植被地上部分碳储量为 $110.14 \mathrm{~g} \mathrm{~m}^{-2}$ 地下根系 $(0 \sim 30 \mathrm{~cm})$ 碳储量为 $2957 \mathrm{~g} \mathrm{~m}^{-2}$ 植被总碳储量为 $3067.14 \mathrm{~g} \mathrm{~m}^{-2}$; 重度退化草地系统中植被地上部分碳储量为 $57.07 \mathrm{~g} \mathrm{~m}^{-2}$, 地下根系 $(0 \sim 30 \mathrm{~cm})$ 碳储量为 $357 \mathrm{~g} \mathrm{~m}^{-2}$ 植被总碳储量为 $414.07 \mathrm{~g} \mathrm{~m}^{-2}$ 。由此可见, 高寒草甸严重退化后, 通过植 物组织流失的碳达到 $2653.35 \mathrm{~g} \mathrm{~m}^{-2}$ 即 $86.5 \%$ 的碳损失; 原生植被封育系统植被总氮储量为 $56.85 \mathrm{~g} \mathrm{~m}^{-2}$, 而重度 退化草地植被总氮储量为 $18.02 \mathrm{~g} \mathrm{~m}^{-2}$, 高寒草甸严重退化使植物组织 $68.30 \%$ 氮损失。与重度退化地相比, 由于 恢复重建措施增加了植物的生物量输入和群落组成, 除翻耕单播处理外, 其它恢复重建措施均能恢复系统植被的 碳氮储量。这些恢复重建措施将会逐步改善土壤的物理和化学特性, 最终使这些生态系统逐步由碳源向碳汇方向 的转变成为可能。

关键词 高寒草甸 草场退化 恢复重建 植被碳氮含量

\section{EFFECTS OF LAND DEGRADATION AND REHABILITATION ON VEGETATION CARBON AND NITROGEN CONTENT OF ALPINE MEADOW IN CHINA}

\author{
WANG Wen-Ying ${ }^{13}$, WANG Qi-Ji ${ }^{2 *}$, WANG Gang ${ }^{3}$, and JING Zeng-Chun ${ }^{2}$ \\ ${ }^{1}$ Key Laboratory of Environment and Resources on Tibetan Plateau, Ministry of Education, Qinghai Normal University , Xining 810001 , China , \\ ${ }^{2}$ Northwest Plateau Institute of Biology , Chinese Academy of Sciences , Xining , 810001 , China , and ${ }^{3}$ College of Life Sciences , Lanzhou University , \\ Lanzhou 730000 , China
}

\begin{abstract}
Aims Our objectives were to compare vegetation biomass and total carbon and nitrogen content of severely degraded grassland and undisturbed Kobresia meadow , and to measure the relative influence of various rehabilitation practices on vegetation biomass and carbon and nitrogen content in early secondary succession.

Methods The research was conducted on alpine meadows in Dari County , Qinghai Province , China , using five treatments : undisturbed native meadow, severely degraded grassland, and three grasslands rehabilitated by different practices (mixed seeded, single seeded and natural recovery). In each treatment, vegetation $\mathrm{C}$ and $\mathrm{N}$ contents were calculated on an area and depth basis from biomass samples and plant concentration analyses.

Important findings In the undisturbed native meadow treatment, total aboveground biomass was $265.1 \mathrm{~g}$ $\mathrm{m}^{-2}$ and root biomass in the uppermost $30 \mathrm{~cm}$ averaged $6982 \mathrm{~g} \mathrm{~m}^{-2}$. In the severely degraded grassland treatment , above ground biomass was only $139.9 \mathrm{~g} \mathrm{~m}^{-2}$ and root biomass was only $916 \mathrm{~g} \mathrm{~m}^{-2}$. Total aboveground biomass in the mixed seeded, single seeded and natural recovery treatments was 307.1, 179.9 and $200.4 \mathrm{~g} \mathrm{~m}^{-2}$, and root biomass was 1323,1169 and $1412 \mathrm{~g} \mathrm{~m}^{-2}$, respectively , after seven growing seasons. Total C content of vegetation in the undisturbed native meadow was $3067.42 \mathrm{~g} \mathrm{~m}^{-2}$, while that of the severely degraded grassland treatment was only $414.07 \mathrm{~g} \mathrm{~m}^{-2}$. Therefore, land degradation leads to loss of $86.5 \%$ of the original plant tissue C. In addition, land degradation leads to loss of $68.3 \%$ of the original
\end{abstract}


plant tissue N. Compared with the severely degraded land, mixed seeded and natural recovery treatments partly recover $\mathrm{C}$ and $\mathrm{N}$ content, indicating that they may be alternative approaches to sequestering $\mathrm{C}$ in former degraded alpine meadow.

Key words alpine meadow, grassland degradation, rehabilitation, vegetation $\mathrm{C}$ and $\mathrm{N}$ content

研究碳循环机理和碳收支评价及其对全球变化 的影响与反馈作用,已成为全球变化和可持续发展 研究中的关键问题之一。青藏高原是地球陆地生态 系统的重要组成部分, 是欧亚大陆最高最大的地貌 单元, 在亚洲气候乃至全球气候变化中扮演重要角 色(程国栋等,1997)。青藏高原广泛分布的高寒草 甸、高寒草原及高寒沼泽草甸草地等均属自然生态 类型，在欧亚大陆具有相当的区域代表性(李文华和 周兴民，1998）。土地退化或退化土地恢复重建都会 使原来的生态系统发生剧烈的改变。这些过程会改 变植被生产力及土壤有机质的积累和分解速率, 进 而影响到生态系统碳、氮循环和土壤碳储量 ( Lal et $a l$. , 1995)。在未来全球变化情景下, 高原土壤层的 碳释放和植被层的碳吸收对全球变化更为敏感, 而 且在区域生态系统碳平衡过程中起着极为重要的作 用。有关青藏高原高寒草甸究竟是碳源 (排放)还是 碳汇 (吸收)、强度有多大等问题, 将是全球变化研究 中的焦点之一。因此, 研究青藏高原高寒草甸土壤 温室气体和碳、氮等元素循环特征，对于评价青藏高 原生物地球化学循环对全球变化的响应和反馈作用 具有重要的科学和实际意义 (Wang et al., 2002)。

近年来在我国的西部大开发中, 采用退耕还林 (还草)及退化草地恢复与重建等生态建设措施, 着 重探讨了防止水土流失、涵养水源、提高生产力、改 变产业结构、增加经济收益等方面的问题, 并未充分 认识到增加碳汇的生态功能。目前有关青藏高原高 寒草甸土地退化及其恢复、重建措施对植被及土壤 碳、氮含量影响研究的报道较少。本文旨在通过高 寒草甸植物碳、氮含量在不同土地利用条件下的特 征及动态变化的研究, 检验土地退化及不同恢复措 施对植被碳氮含量的影响, 为高寒草甸碳、氮循环机 理和碳、氮收支评价提供理论依据和基础数据。

\section{1 研究地区自然地理概况}

青海省果洛藏族自治州达日县, 位于青藏高原 东南、青海省南部, 地处 $32^{\circ} 36^{\prime} 42^{\prime \prime} \sim 34^{\circ} 15^{\prime} 20^{\prime \prime} \mathrm{N}$,98 $15^{\prime} 29^{\prime \prime} \sim 100^{\circ} 32^{\prime} 41^{\prime \prime} \mathrm{E}$ 。全县土地面积为 1.62 万 $\mathrm{km}^{2}$ 。境内巴颜喀拉山由西北向东南横贯全境 其地
势西北高而东南低。海拔高度多在 $4000 \mathrm{~m}$ 以上。 气候属高寒半湿润性类型, 年平均气温为 $-1.3{ }^{\circ} \mathrm{C}$, 7 月平均气温为 $9.1{ }^{\circ} \mathrm{C}, 1$ 月平均气温为 $-12.9{ }^{\circ} \mathrm{C}$ 。 县境内 $\geqslant 0{ }^{\circ} \mathrm{C}$ 的积温在 $751.9 \sim 1070.7{ }^{\circ} \mathrm{C}$ 之间。年 降雨量 486.9 666.5 mm 之间,多集中在 5 9 月, 期间降水量占年降水量的 $85 \%$ 。全年蒸发量为 $1119.07 \mathrm{~mm}$ 。年总辐射量在 $623.8 \sim 629.9 \mathrm{~kJ} \mathrm{~cm}{ }^{-2}$ 之间。全县草地面积为 140.17 万 $\mathrm{hm}^{2}$, 占总土地面 积的 $94 \%$;可利用草地的面积 111.724 万 $\mathrm{hm}^{2}$ 。草 地类型主要以高寒草甸为主, 土壤类型以高山草甸 土为主(史惠兰等 2005)。

\section{2 材料和方法}

\section{1 样地设置}

研究于 2004 年 $7 \sim 8$ 月在果洛州达日县窝赛乡 进行, 试验样地选择不同土地利用和管理条件下的 植物群落。包括于 1998 年 5 6 月, 采用人工措施 恢复重建的人工和重度退化草地, 并以 1998 年同步 封育未退化的原生嵩草草甸作对照, 共 5 个处理 :1) 封育的高寒嵩草草甸原生植被 ( (1),YF) ;2) 老芒麦 (Elymus sibiricus) + 冷地早熟禾 (Poa crymophila) 混 播 (2),HB) 3) 老芒麦翻耕单播 (3),DBF) ;4)退化草 地封育自然恢复处理 (4),NR);5) 重度退化草地 (5) SDL)。每个处理选择 3 个植被较为均匀, 面积 为 $50 \mathrm{~m} \times 50 \mathrm{~m}$ 的样地为固定观察测定样地。本研 究所用处理为: 两个 7 龄的人工草地群落 ( HB 和 DBF) ,1 个封育 7 年的嵩草草甸原生植被( YF ) , 1 个 封育 7 年重度退化草地群落 (NR) 和 1 个未封育自 然状态的重度退化草地群落 (SDL)。

人工草地重建措施如下: 人工草地, 首先将重度 退化地翻耕 1 遍 然后用圆盘耙耙磨整地, 再将种子 和底肥 (二铵)混合撒播, 再用轻型圆盘耙耙磨覆种、 最后用镇压器镇压 1 遍 椫播老芒麦播种量为 37.5 $\mathrm{kg} \mathrm{hm}^{-2}$ 混播处理时老芒麦播种量为 $20 \mathrm{~kg} \mathrm{hm}^{-2}$, 冷地早熟禾播种量为 $15 \mathrm{~kg} \mathrm{hm}^{-2}$ 播深 $3 \sim 4 \mathrm{~cm}$ 。人 工草地建植后第一年到第二年的牧草生长期绝对禁 牧, 此后各处理区均可在冬季枯草期(10 月～翌年 5 月)放牧，夏季生长季( $6 \sim 9$ 月) 禁牧。

\section{2 生物量测定}


地上生物量测定于 2004 年 8 月底生物量高峰 期测定, 在每个处理样地, 用收割法测定地上生物 量, 随机设置 5 个 $50 \mathrm{~cm} \times 50 \mathrm{~cm}$ 的样方, 将样方中的 植物齐地表剪下, 收获的植物按禾草类、莎草类和杂 类草功能群分类。根系生物量在 3 个 $25 \mathrm{~cm} \times 25$ $\mathrm{cm}$ 深 $30 \mathrm{~cm}$ 的土坑中取样, 土块过 $4 \mathrm{~mm}$ 篮分出根 系 然后将分出的根系放在 $0.25 \mathrm{~mm}$ 的篮上用水冲 洗, 得到根系。所有收获的植物材料在 $70{ }^{\circ} \mathrm{C}$ 的恒温 箱中烘 $24 \mathrm{~h}$ 烘至衡重后称取干重, 文中生物量以烘 干重计。

各处理植物样品粉碎后在 Vario EL III 元素分 析仪上分析总碳、总氮浓度 (由兰州大学分析测试中
心承担完成)。

\section{3 计算与统计分析}

用方差分析 (ANOVA, $L S D)$ 和 $t$ 检验比较不同 处理间各参数差异显著性 统计分析均在 Excel 2003 和 SPSS 11.0 统计软件上完成。

\section{3 研究结果}

\section{1 不同土地管理措施下地上生物量比较}

由表 1 可以看出, YF 地上总生物量为 $265.1 \mathrm{~g}$ $\mathrm{m}^{-2}$, HB 和 DBF 处理中地上总生物量分别为 $\mathrm{YF}$ 的 $116 \%$ 和 $68 \%$ 。 NR 和 SDL 地上总生物量分别为 $\mathrm{YF}$ 的 $76 \%$ 和 $53 \%$ 。

表 1 不同处理禾草、杂草和莎草地上平均生物量 $( \pm$ 标准误)

Table 1 Mean biomass $( \pm S E)$ of grasses, forbs and sedges in different treatments $\left(\mathrm{g} \mathrm{m}^{-2}\right)$

\begin{tabular}{|c|c|c|c|c|}
\hline & $\begin{array}{c}\text { 禾草 } \\
\text { Grasses }\end{array}$ & $\begin{array}{l}\text { 杂草 } \\
\text { Forbs }\end{array}$ & $\begin{array}{l}\text { 莎草 } \\
\text { Sedges }\end{array}$ & $\begin{array}{c}\text { 总地上生物量 } \\
\text { Total aboveground biomass }\end{array}$ \\
\hline $\mathrm{YF}$ & $109.7(5.6)^{b}$ & $65.6(17.5)^{\mathrm{c}}$ & $89.7(18.8)^{\mathrm{a}}$ & $265.1(27.1)^{\mathrm{ab}}$ \\
\hline $\mathrm{HB}$ & $295.2(39.4)^{\mathrm{a}}$ & $11.9(2.3)^{\mathrm{d}}$ & $0.0(0.0)^{\mathrm{b}}$ & $307.1(39.0)^{\mathrm{a}}$ \\
\hline $\mathrm{DBF}$ & $170.1(24.8)^{\mathrm{b}}$ & $9.7(2.9)^{\mathrm{d}}$ & $0.0(0.0)^{\mathrm{b}}$ & $179.9(22.0)^{\mathrm{c}}$ \\
\hline NR & $1.2(0.8)^{\mathrm{c}}$ & $198.8(14.7)^{\mathrm{a}}$ & $0.4(0.4)^{\mathrm{b}}$ & $200.4(14.5)^{\mathrm{bc}}$ \\
\hline SDL & $0.0(0.0)^{\mathrm{c}}$ & $139.9(22.9)^{\mathrm{b}}$ & $0.0(0.0)^{\mathrm{b}}$ & $139.9(22.9)^{\mathrm{c}}$ \\
\hline
\end{tabular}

不同字母表示平均值间差异显著 Means with the different letters were significantly different (ANOVA, LSD comparison , $\alpha=0.05$ ) YF : 封育的原 生植被 A non-disturbed native alpine meadow HB : 混播处理 Mixed seeded treatments DB : 单播处理 A single seeded treatment NR :退化草地封育自 然恢复处理 A non-seeded natural recovery treatment SDL : 重度退化草地 A severely degraded treatment

其中, 禾草类生物量依次为 $\mathrm{HB}>\mathrm{DBF}>\mathrm{YF}>$ $\mathrm{NR}>\mathrm{SDL}$;杂类草生物量依次为 $\mathrm{NR}>\mathrm{SDL}>\mathrm{YF}>$ $\mathrm{HB}>\mathrm{DBF}$ 莎草类生物量在 $\mathrm{YF}$ 中占明显的优势, NR 处理中少量出现, HB、DBF 和 SDL 中没有出现。方 差分析表明,HB 处理禾草生物量与其它处理差异显 著; DBF、YF 处理间禾草生物量差异不显著, 而与 NR、SDL 处理差异显著; NR 与 SDL 处理禾草生物量 差异不显著。 YF 处理杂草生物量与 HB、DBF、NR、 SDL 处理杂草生物量差异显著; NR 处理与 SDL 处理 间以及与其它处理间杂草生物量差异显著。HB、 DBF 处理间杂草生物量差异不显著。原生植被封育 处理中莎草生物量显著高于其它处理, 而其它各处 理间莎草生物量差异不显著。

由此可以看出: 人工种植措施可以有效恢复退 化草地地上生物量, 尤其是禾草类生物量更为明显 ; 退化草地封育自然恢复 7 年后, 地上生物量恢复效 果也较好, 但地上生物量绝大多数是由杂类草所贡 献。

\section{2 不同土地管理措施下植物根系生物量比较}

由表 2 可知, 不同土地管理措施下植物根系生
物量依次为 $\mathrm{YF}>\mathrm{NR}>\mathrm{HB}>\mathrm{DBF}>\mathrm{SDL}$ 。其中, 原生 植被封育处理的根系生物量显著高于其它处理。不 同处理区地下生物量垂直分布格局基本相似, 主要 分布在 $0 \sim 10 \mathrm{~cm}$ 土层中 约占地下总生物量 74\% 93\%, YF 和 HB 处理 10 20 cm 土层中根系生物量 略高于其它处理 约占地下总生物量的 $20 \%, 20 \sim 30$ $\mathrm{cm}$ 土层中根系生物量均小于 $6 \%$ 。

表 2 不同处理区地下根系生物量 ( \pm 标准误) 及各层根系生物量 占总地下根系生物量的比例

Table 2 Mean belowground root biomass $( \pm S E)$ and the proportion of belowground biomass in each layer to total belowground biomass in different treatments

\begin{tabular}{lccccc}
\hline & $\begin{array}{c}\text { 总根系生物量 } \\
\text { Total root bio- } \\
\text { mass }\left(\mathrm{g} \mathrm{m}^{-2}\right)\end{array}$ & & \multicolumn{3}{c}{$\begin{array}{c}\text { 各层根生物量占总生物量的比例 } \\
\text { Root biomass percentage of each layer } \\
\text { to total root biomass }(\%)\end{array}$} \\
\cline { 2 - 3 } \cline { 5 - 6 } & $0 \sim 30 \mathrm{~cm}$ & & $0 \sim 10 \mathrm{~cm}$ & $10 \sim 20 \mathrm{~cm}$ & $20 \sim 30 \mathrm{~cm}$ \\
\hline $\mathrm{YF}$ & $6982(451)^{\mathrm{a}}$ & $75(1)^{\mathrm{c}}$ & $21(2)^{\mathrm{a}}$ & $4(1)^{\mathrm{ab}}$ \\
$\mathrm{HB}$ & $1323(157)^{\mathrm{b}}$ & $74(4)^{\mathrm{c}}$ & $20(4)^{\mathrm{a}}$ & $6(0)^{\mathrm{a}}$ \\
$\mathrm{DBF}$ & $1169(237)^{\mathrm{b}}$ & $82(5)^{\mathrm{bc}}$ & $13(2)^{\mathrm{ab}}$ & $5(4)^{\mathrm{ab}}$ \\
$\mathrm{NR}$ & $1412(596)^{\mathrm{b}}$ & $93(1)^{\mathrm{a}}$ & $6(1)^{\mathrm{b}}$ & $1(0)^{\mathrm{b}}$ \\
$\mathrm{SDL}$ & $916(47)^{\mathrm{b}}$ & $92(1)^{\mathrm{a}}$ & $7(1)^{\mathrm{b}}$ & $1(0)^{\mathrm{b}}$ \\
\hline \multicolumn{2}{c}{ 表注见表 1}
\end{tabular}

表注见表 1 Notes see Table 1 
3.3 不同土地管理措施下禾草、杂草和莎草的碳氮 浓度和碳氮比

不同土地管理措施下禾草类、杂类草和莎草类 地上部分的碳、氮浓度及碳氮比 (表 3)。

从各处理平均值看 禾草类、杂类草和莎草类的 碳浓度平均为 $39.33 \% 、 40.66 \%$ 和 $40.86 \%$ 禾草类、 杂类草和莎草类的氮浓度平均为 $1.246 \% 、 1.434 \%$ 和 $1.200 \%$, 可以看出杂草的氮浓度比禾草高; 它们 的碳氮比分别为 $32.38 、 28.60$ 和 34.05 。

通过 Ono-Sample $t$ 检验，禾草类、杂类草和莎草
类碳浓度在各处理间显著性概率分别为 0.890 、 0.997 和 0.972 远大于 5\%。禾草类、杂类草和莎草 类氮浓度在各处理间显著性概率分别为 0.993 、 0.932 和 0.984 , 远大于 $5 \%$ 。因此, 可以认为不同处 理对禾草类、杂类草、莎草类植物碳、氮浓度含量的 影响不大, 差异不显著 $(p>0.05)$ 。但从测定结果 看, $\mathrm{YF} 、 \mathrm{HB} 、 \mathrm{DBF}$ 处理禾草类碳浓度比较相近, 但高 于退化草地 NR 和 SDL 处理, 其差异可能来自物种 组成的差异或土壤养分的不同。

表 3 不同处理禾草类、杂类草和莎草类地上部分碳氮浓度 $(\%)$ 及碳氮比

Table 3 Concentrations of $\mathrm{C}$ and $\mathrm{N}$ and $\mathrm{C} / \mathrm{N}$ ratio of grasses, forbs and sedges of aboveground vegetation under different treatments

\begin{tabular}{|c|c|c|c|c|c|c|c|c|c|}
\hline & \multicolumn{3}{|c|}{ 禾草类 Grasses } & \multicolumn{3}{|c|}{ 杂类草 Forbs } & \multicolumn{3}{|c|}{ 莎类草 Sedges } \\
\hline & $\mathrm{C}(\%)$ & $\mathrm{N}(\%)$ & $\mathrm{C} / \mathrm{N}$ & $\mathrm{C}(\%)$ & $\mathrm{N}(\%)$ & $\mathrm{C} / \mathrm{N}$ & $\mathrm{C}(\%)$ & $\mathrm{N}(\%)$ & $\mathrm{C} / \mathrm{N}$ \\
\hline YF & 40.48 & 1.27 & 31.92 & 43.93 & 1.53 & 28.75 & 41.15 & 1.22 & 33.75 \\
\hline $\mathrm{HB}$ & 40.55 & 1.02 & 39.91 & 41.13 & 1.39 & 29.44 & - & - & - \\
\hline DBF & 41.47 & 1.09 & 38.05 & 40.83 & 1.23 & 33.33 & - & - & - \\
\hline NR & 35.48 & 1.36 & 26.09 & 36.64 & 1.41 & 25.94 & 40.25 & 1.18 & 34.11 \\
\hline SDL & 38.69 & 1.49 & 25.93 & 40.79 & 1.59 & 25.53 & - & - & - \\
\hline 平均 Average & 39.33 & 1.25 & 32.28 & 40.66 & 1.43 & 28.60 & 40.86 & 1.20 & 33.92 \\
\hline
\end{tabular}

YF、HB、DBF、NR、SDL :见表 1 See Table 1

3.4 不同土地管理措施下植被地上部分单位面积 碳氮储量

由图 1 可知,各处理单位面积植被地上部分碳 总储量依次为 $\mathrm{HB}\left(124.60 \mathrm{~g} \mathrm{~m}^{-2}\right)>\mathrm{YF}(110.14 \mathrm{~g}$ $\left.\mathrm{m}^{-2}\right)>\operatorname{DBF}\left(81.96 \mathrm{~g} \mathrm{~m}^{-2}\right)>\operatorname{NR}\left(73.43 \mathrm{~g} \mathrm{~m}^{-2}\right)>$ SDL $\left(57.07 \mathrm{~g} \mathrm{~m}^{-2}\right)$ 。

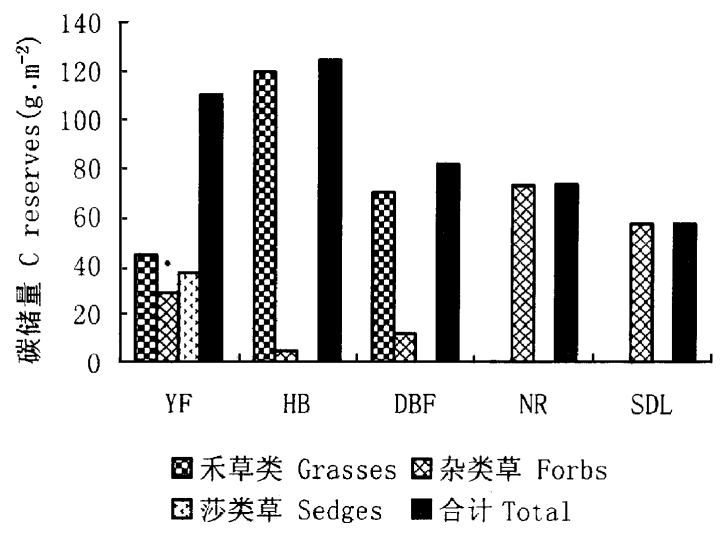

图 1 不同处理植被地上部分单位面积碳储量

Fig.1 Carbon reserves of aboveground vegetation in different treatments

YF、HB、DBF、NR、SDL :见表 1 See Table 1

其中, $\mathrm{YF}$ 处理的总碳储量依次由禾草类、杂类 草和莎草类所贡献，分别占总碳储量的 $40.32 \%$ 、
$26.17 \%$ 和 $33.51 \%$,HB、DBF 处理主要由禾草类所 贡献，分别占总碳储量的 $96.07 \%$ 和 $85.20 \%$,NR、 SDL 处理总碳储量主要由杂类草所贡献, 分别占总 碳储量的 $99.20 \%$ 和 $100 \%$ 。

不同处理区单位面积植被地上部分氮储量依次 为 $\mathrm{YF}\left(3.49 \mathrm{~g} \mathrm{~m}^{-2}\right)>\mathrm{HB}\left(3.16 \mathrm{~g} \mathrm{~m}^{-2}\right)>\mathrm{NR}(2.83$ $\left.\mathrm{g} \mathrm{m}^{-2}\right)>\operatorname{SDL}\left(2.24 \mathrm{~g} \mathrm{~m}^{-2}\right)>\operatorname{DBF}\left(2.20 \mathrm{~g} \mathrm{~m}^{-2}\right)$ 。 各处理区禾草类、杂类草和莎草类地上部分氮储量 对总氮贡献率变化趋势 (图 2) 与总碳变化趋势相 似。

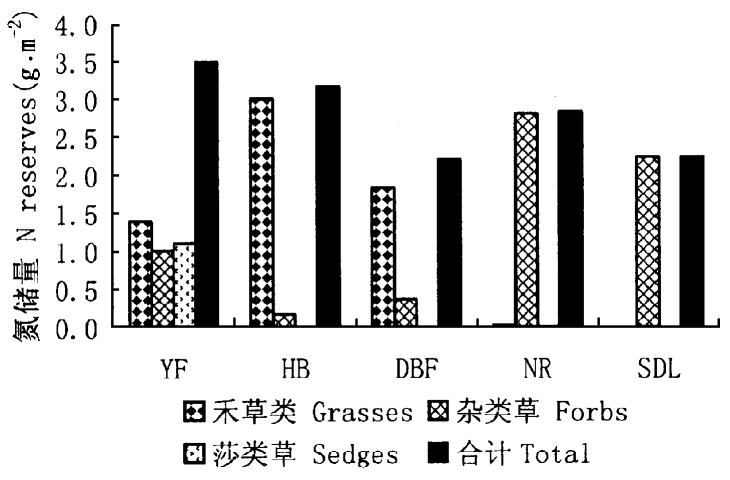

图 2 不同处理植被地上部分单位面积氮储量

Fig.2 Nitrogen reserves of aboveground vegetation in different treatments

YF、HB、DBF、NR、SDL :见表 1 See Table 1 
3.5 不同土地管理措施下植物根系碳氮浓度、碳氮 比及单位面积碳氮含量

原生植被封育处理地下 $0 \sim 30 \mathrm{~cm}$ 层根组织碳 浓度最高，达 $42.51 \%$ （表 4）,显著高于自然恢复处 理和所有的人工种植处理, 另外, 自然封育处理下根 组织碳浓度显著高于翻耕单播处理根中碳浓度; 各 处理根组织中氮浓度高低顺序为:重度退化处理 > 自然封育处理 > 人工种植处理 > 原生植被封育处 理, 人工种植处理间根组织氮浓度差异不显著。原 生植被封育处理根组织碳氮比最高, 达 56.02 , 显著 高于其它处理根组织碳氮比, 且其它处理间碳氮比 无显著性差异。

从表 4 可以看出 地下 $0 \sim 30 \mathrm{~cm}$ 层根系中每平 方米碳含量和氮含量均在原生植被封育处理中最 高，显著高于其它处理，且其它处理间差异不显著，
但从测定数值看, 自然封育和混播处理中根系中碳 含量和氮含量比单播处理和重度退化处理高。原生 植被封育处理根系中碳含量为 $2957 \mathrm{~g} \mathrm{~m}^{-2}$, 氮含量 为 $53.36 \mathrm{~g} \mathrm{~m}^{-2}$; 重度退化处理根系中的碳含量为 $357 \mathrm{~g} \mathrm{~m}^{-2}$, 氮含量为 $15.78 \mathrm{~g} \mathrm{~m}^{-2}$, 这意味着从原生 植被退化演替成重度退化草地后, 仅从根系中丢失 的碳和氮就分别达 2600 和 $37.58 \mathrm{~g} \mathrm{~m}^{-2}$, 即土地退 化导致由根系流失的碳和氮分别达到 $88 \%$ 和 $70 \%$ 。 混播处理根系碳、氮含量分别为原生植被封育处理 的 $15.5 \%$ 和 $32.0 \%$ ，单播处理根系碳、氮含量分别 为原生植被封育处理的 $12 \%$ 和 $28 \%$ ，自然封育根系 碳、氮含量分别为原生植被封育处理的 $17.6 \%$ 和 $41.5 \%$ 相比较而言, 恢复地下根系碳氮效果较好的 措施是自然恢复和混播处理。

表 4 不同处理 $0 \sim 30 \mathrm{~cm}$ 层根系碳、氮浓度和碳、氮比及单位面积碳氮储量

Table 4 Concentrations of $\mathrm{C}$ and $\mathrm{N}, \mathrm{C} / \mathrm{N}$ ratio and $\mathrm{C}, \mathrm{N}$ reserves per unit area in $0-30 \mathrm{~cm}$ depths under different treatments $\left(\mathrm{g} \mathrm{m}^{-2}\right)$

\begin{tabular}{cccccc}
\hline $\begin{array}{c}\text { 处理 } \\
\text { Treatments }\end{array}$ & $\begin{array}{c}\text { 碳浓度 } \\
\text { C concentration }(\%)\end{array}$ & $\begin{array}{c}\text { 氮浓度 } \\
\text { N concentration }(\%)\end{array}$ & $\begin{array}{c}\text { 碳氮比 } \\
\text { C/N ratio }\end{array}$ & $\begin{array}{c}\text { 单位面积碳储量 } \\
\text { C content per unit area } \\
\left(\mathrm{g} \mathrm{m}^{-2}\right)\end{array}$ & $\begin{array}{c}\text { 单位面积氮储量 } \\
\mathrm{N} \text { content per unit area } \\
\left.(\mathrm{g} \mathrm{m})^{-2}\right)\end{array}$ \\
\hline $\mathrm{YF}$ & $42.51(1.27)^{\mathrm{a}}$ & $0.764(0.041)^{\mathrm{d}}$ & $56.02(3.88)^{\mathrm{a}}$ & $2957(115)^{\mathrm{a}}$ & $53.36(4.74)^{\mathrm{a}}$ \\
$\mathrm{HB}$ & $34.90(1.17)^{\mathrm{bc}}$ & $1.298(0.045)^{\mathrm{c}}$ & $26.90(0.48)^{\mathrm{b}}$ & $458(41)^{\mathrm{b}}$ & $17.08(1.73)^{\mathrm{b}}$ \\
$\mathrm{DBF}$ & $30.19(1.15)^{\mathrm{c}}$ & $1.244(0.110)^{\mathrm{c}}$ & $24.49(1.31)^{\mathrm{b}}$ & $358(84)^{\mathrm{b}}$ & $15.06(4.11)^{\mathrm{b}}$ \\
$\mathrm{NR}$ & $36.71(1.49)^{\mathrm{b}}$ & $1.529(0.048)^{\mathrm{b}}$ & $24.05(1.30)^{\mathrm{b}}$ & $520(227)^{\mathrm{b}}$ & $22.15(9.98)^{\mathrm{b}}$ \\
$\mathrm{SDL}$ & $38.80(2.27)^{\mathrm{ab}}$ & $1.721(0.069)^{\mathrm{a}}$ & $22.51(0.56)^{\mathrm{b}}$ & $357(34)^{\mathrm{b}}$ & $15.78(1.11)^{\mathrm{b}}$ \\
\hline
\end{tabular}

表注见表 1 Notes see Table 1

\section{4 讨 论}

\section{1 原生植被封育处理与重度退化处理间比较}

在高寒嵩草草甸，由于豆科植物缺乏使生物固 氮量较低, 且根密度在 $0 \sim 10 \mathrm{~cm}$ 层非常大, 土壤中 速效氮绝大部分以铵态氮形式存在 (曹广民和张金 霞 2001）,此外,原生植被土壤中保留着大量的死 根，它们的氮浓度较低（李文华和周兴民，1998），这 些原因可能是导致原生植被封育草地根系氮浓度较 低的原因之一。此外, 由于原生植被封育处理的根 系碳氮比较高, 再加上高寒草甸土壤温度和土壤微 生物活性较低, 导致大量分解速率慢的碳储存在地 下,也是高寒草甸土中能储存大量根系的原因之一。

$\mathrm{YF}$ 中植被地上部分碳储量为 $110.14 \mathrm{~g} \mathrm{~m}^{-2}$ 地 下根系 $(0 \sim 30 \mathrm{~cm})$ 碳储量为 $2957.00 \mathrm{~g} \mathrm{~m}^{-2}$ 植物总 碳储量为 $3067.14 \mathrm{~g} \mathrm{~m}^{-2}$;SDL 中植被地上部分碳 储量为 $57.07 \mathrm{~g} \mathrm{~m}^{-2}$ 地下根系 $(0 \sim 30 \mathrm{~cm})$ 碳储量为 $357.00 \mathrm{~g} \mathrm{~m}^{-2}$,植物总碳储量为 $414.07 \mathrm{~g} \mathrm{~m}^{-2}$ 。因
此高寒草甸草地严重退化后, 通过植被组织固定的 碳减少 $2653.07 \mathrm{~g} \mathrm{~m}^{-2}$,即高寒嵩草草地严重退化将 导致原系统植被中 $86.50 \%$ 的碳损失。

$\mathrm{YF}$ 群落中植被地上部分氮储量为 $3.49 \mathrm{~g} \mathrm{~m}^{-2}$, 地下根系 $(0 \sim 30 \mathrm{~cm})$ 氮储量为 $53.36 \mathrm{~g} \mathrm{~m}^{-2}$ 。植物 总氮储量为 $56.85 \mathrm{~g} \mathrm{~m}^{-2}$, 而且 SDL 中植物地上、地 下部分氮储量分别为 2.24 和 $15.78 \mathrm{~g} \mathrm{~m}^{-2}$,植物总 氮储量为 $18.02 \mathrm{~g} \mathrm{~m}^{-2}$ 。高寒嵩草草甸严重退化后, 植物组织固定的氮减少 $38.83 \mathrm{~g} \mathrm{~m}^{-2}$, 即高寒嵩草草 甸土地退化导致原系统植被中 $68.30 \%$ 的氮损失。 高寒嵩草草甸植物碳氮主要储存在根系中, 这将对 保持生态系统碳氮循环的相对稳定性起到很重要的 作用。由此可见，高寒草甸生态系统退化、植被破坏 和生物量减少, 不仅造成土壤碳氮补充的减少, 而且 使碳氮流失的数量增大。

\section{2 恢复重建处理间比较研究}

$\mathrm{NR}$ 处理中 植物总碳储量为 $593.43 \mathrm{~g} \mathrm{~m}^{-2}$,总 氮含量为 $24.98 \mathrm{~g} \mathrm{~m}^{-2}$; $\mathrm{HB}$ 处理中植物总碳含量为 
$582.60 \mathrm{~g} \mathrm{~m}^{-2}$,总氮含量为 $20.24 \mathrm{~g} \mathrm{~m}^{-2}$; DBF 处理 中植物总碳含量为 $433.96 \mathrm{~g} \mathrm{~m}^{-2}$ 总氮含量为 17.26 $\mathrm{g} \mathrm{m}^{-2}$ 。这些结果表明, 通过 7 年的群落演替, SDL 通过人工恢复措施干扰后较重度退化草地自然状态 (SDL) (植物总碳储量为 $414.07 \mathrm{~g} \mathrm{~m}^{-2}$,总氮储量为 $18.02 \mathrm{~g} \mathrm{~m}^{-2}$ )下植被的碳氮储量有所增加, 这主要 归功于恢复重建措施增加了植物生物量。因此, 将 重度退化草地通过封育自然恢复或混播、单播恢复 重建多年生植被都可以作为高寒草甸生态系统吸收 固定碳(碳汇)的一个途径。

在我们的研究中, 与原生嵩草草甸相比较, 土地 利用变化或土地退化对重建草地植被特性的影响仍 然是明显的, 但与退化草地自然状态相比较, 草地恢 复与重建可以增加地表覆盖度、地上和地下生物量 及植被中的碳氮储量。这些恢复与重建措施将会逐 步的改善土壤的物理和化学特性。正如 Baer (2001) 所言: 在绝大多数恢复重建研究中, 退化地完 全靠人为恢复到原始状态是不大可能的，如果恢复 的状态比未恢复状态更有价值, 那么, 恢复或重建措 施就是一个恰当的选择。

\section{参 考 文 献}

Baer SG (2001). Changes in Ecosystem Function and Effects of Environmental Complexity on Floristic Diversity During Tallgrass Prairie Restoration. PhD dissertation, Kansas State University. ProQuest Information and Learning (UMI), Ann Arbor, MI. Cao GM (曹广民), Zhang JX (张金霞)（2001）. Soil nutrition and substance cycles of Kobersia meadow. In: Zhou XM (周兴 民) ed. Chinese Kobersia Meadow (中国嵩草草甸). Science Press, Beijing, $188-216$. (in Chinese)

Cheng GD (程国栋), Li PJ (李培基), Zhang XS (张祥松) (1997). Assessment About Effects of Climatic Change on Accumulated Snow, Glacier and Frozen Soil (冰川与冻土). Gansu Culture Press, Lanzhou, 22 - 56. (in Chinese)

Lal R, Fausey NR, Eckert DJ (1995). Land use and soil management effects on emissions of radiatively active gases from two soils in Ohio. In: Lal R, Kimble J, Levine E, Stewart BA eds. Soil Management and Greenhouse Effect. CRC Press, Boca Raton, FL, $41-59$.

Li WH (李文华), Zhou XM (周兴民)（1998）。 Ecosystems of Tibetan Plateau and Approach for Their Sustainable Management (青藏高原生态系统及优化利用模式). Guangdong Science \& Technology Press, Guangzhou, 203-228. (in Chinese)

Shi HL (史惠兰), Wang QJ (王启基), Jing ZC (景增春), Wang CT (王长庭), Wang J (王杰), Wang LY (王柳英) (2005). The structure, biodiversity and stability of artificial grassland plant communities in the source regions of the Yangze and Yellow River. Acta Prataculturae Sinica (草业学报), 14 (3) , 23-30. (in Chinese with English abstract)

Sun HL (孙鸿烈) (1996). Formation, Evolution and Development of Qinghai-Xizang ( Tibetan) Plateau (青藏高原形成、演化与 发展). Shanghai Science \& Technology Press, Shanghai, 168 192. (in Chinese)

Wang GX, Qian J, Cheng GD, Lai YM (2002). Soil organic carbon pool of grassland soils on the Qinghai-Tibetan plateau and its global implication. The Science of the Total Environment, 291, $207-217$. 